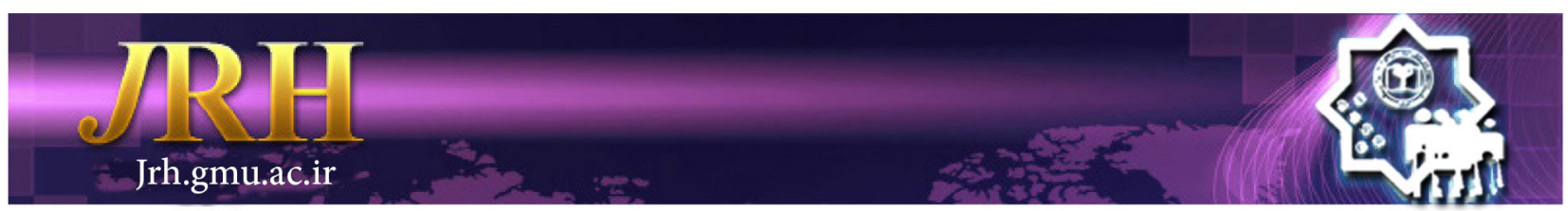

\title{
Effect of behavioral-communication couple therapy in dimensions of marital adjustment in infertile couples
}

\author{
Shahriar Dargahi ${ }^{1}$, Hossein Ghamari Giv ${ }^{1}$, Nader Aeyadi ${ }^{2}$, Ziba Soltani ${ }^{3}$
}

\author{
Journal of Research \& Health \\ Social Development \& Health Promotion \\ Research Center \\ Vol. 8, No. 4, Jul \& Aug 2018 \\ Pages: $313-321$ \\ DOI: $10.29252 /$ jrh.8.4.313 \\ Original Article
}

1. Faculty of Education Sciences and Psychology, University of Mohaghegh Ardabili, Ardabil, Iran

2. Faculty of Psychology and Educational Sciences, Kharazmi University, Tehran, Iran

3. Department of Counseling, Faculty of Psychology and Education Sciences, Payame Noor University, Tehran, Iran

Correspondence to: Shahriar Dargahi, Faculty of Education Sciences and Psychology, University of Mohaghegh Ardabili, Ardabil, Iran

Email: shahriardargahi@yahoo.com

Received: 27 Dec 2014

Accepted: 28 Jun 2015

How to cite this article: Dargahi Sh, Ghamari Giv H, Aeyadi N, Soltani Z. Effect of behavioral-communication couple therapy in Dimensions of marital adjustment in infertile couples. J Research Health2018; 8(4): 313321 .

\begin{abstract}
There are different therapy approaches used by family therapy researchers over the years to evaluate their reliability and effect in couples. Bernstein's approach of behavioral-communication is one of these approaches. Accordingly, the current research aimed to survey the effectiveness of behavioral-communication couple therapy in improving dimensions of marital adjustment among infertile couples. This quasi-experimental research was designed as pretest-posttest and employed control group. 40 couples referring to the Gynecology centers was selected through convenience sampling method and assigned into two groups of experimental and control. At the beginning of the study, pretest was performed on both groups and then, an intervention (based on Berneshtain behavioral-communication couple therapy) was conducted during 10 sessions of 90 minutes (one session per week). After completion of the treatment program, the posttest was performed. Also, the follow-up stage was performed on both groups 2.5 months later to evaluate the stability of therapeutic intervention. The tool used in this research was Spinner adjustment questionnaire. The results showed that after behavioral communication training, a significant difference was observed in the dimensions of marital adjustment among infertile couples between the experimental and control groups. The results showed that couple therapy with behavioral communication method is effective in increasing adjustment and its dimensions. In fact, this study showed that behavioral-communication couple therapy increased agreement among infertile couples by improving communication skills and reducing conflicts.
\end{abstract}

Keywords: Adjustment, Communication, Couple Therapy, Infertility

\section{Introduction}

One of the issues affecting the relationship between couples is having a child. When fertility is delayed or it is failed unwillingly, the couple's relationship is affected. In today's world, the infertility has become a social concern, and can create huge psychological problems among the couples [1]. Infertile couples are those who have decided to conceive a pregnancy without the use of contraceptives since at least one year ago, but they have no children, 
and the medical specialist diagnoses the infertility [2]. The World Health Organization has recognized infertility as a reproductive health problem that although is not a disease, it can cause important emotional disorders, and create social and psychological consequences [3]. Infertility is among stressors that strongly affects psychological structure and interpersonal relationships [4]. Although infertility is remarkable as a life disturbing event, its divergent outcomes on personal, interpersonal, and social levels warn the importance of this phenomenon in society. Many studies have shown that infertility experience is associated with a wide range of psychological damage, including destruction of self-esteem, increased levels of stress, anxiety, depression, feeling of inferiority and inadequacy, sexual inaction, and marital problems [5,6]. Although infertility may be the problem of one of the couple, because marriage is a shared process, both of them are affected. Infertility is a very stressful change for marital and family life, and creates significant problems in couples' relationships [7]. One of these problems is the negative impact on marital fertility and sexual function [8].

Marital adjustment is the situation in which the couples often have feeling of happiness and satisfaction. It is the process that occurs during the life of the couples, and demands compliance tastes, personality traits, establishing rules of behavior, and the formation of interactional patterns [9]. It is a multidimensional term that clarifies multiple levels of marital adjustment such as consistency, happiness, solidarity, and commitment [10]. Marital adjustment is important, particularly when various factors including infertility affect the couple's relationships [11]. Infertility indicates a kind of stress, which has become the biggest obsession in life, and causes a decrease in marital satisfaction and alienation from family, and thus negatively affects marital relationship [12]. Infertility also affects some aspects of marital satisfaction including intimacy, sexuality, relationships, and conflicts [13].

There are different approaches in the field of couple therapy that family therapy researchers have been looking for their reliability and effectiveness over the years [14]. One of these approaches is behavioral-communication approach that has been developed By Philip Berneshtain and Berneshtain. The behavioralcommunication approach is theoretical and practical combination of cognitive and behavioral system-based approaches. The behavioral-communication pattern offers a series of clinical therapies that its distinguishable facet is disassembling three systems (behavioral, communicational, and cognitive) and has been adopted over the past decade [15].

This approach is based on those therapy approaches that are used to solve problems related to communication of couples. Based on behavioral-communication pattern, the behavior of spouse should be evaluated in the context of a relationship. Although a behavior may express person's needs, it may have an important function in marital life [16]. In addition, the spouses, who have problems in the marriage, have a lot of difficulties in solving the problems, which doubles their need to get help of experienced consultants. This approach provides practical guidance available for counselors to correct the spouses' relationships, and assist them in solving their dispute through objective and behavioral methods [16]. Performing program to avoid confusion and conflict using behavioral and communication skills and conflict management techniques can cause couples to demonstrate a higher level of communication skills and show a lower level of inconsistency in behavior and communication [17]. Many studies have shown the effectiveness of the approach on the marital problems of couples. Sodani, Nazarifard, and Mehrabizade [15] in a study concluded that the couples, who received the behavioral-communication marital therapy, compared to the counterparts in the control group, after the completion of therapy, had lower conflicts. Johnson, Cohen, David, Lawrence, Rogge, and Karney [18] investigated the effect of communication skills training and marital problem solving on the 
improvement of interactions between husband and wife and their adjustment. Hoyer, Uhmann, Rambow, and Jacobi [19] concluded that the use of combined behavioral, communicational, and cognitive techniques increases the emotional and sexual intimacy in couples. Considerable studies have been carried out dealing with this type of therapy. For example, Nazari showed that the behavior enrichment program was effective in various aspects of marital adjustment, intimacy, and marital satisfaction [20]. The study of Murry et al. [21] showed that behavior enrichment program had a significant effect on commitment and marital adjustment. Furthermore, Shollenberger [22] indicated the impact of relationship enrichment in agreement, solidarity, and marital adjustment. Based on the above background and the problems associated with communication and compatibility among infertile couples, numerous studies have been focused on the problems of infertile couples. However, a few studies have been conducted to treat the communication issues of the infertile couples. This study attempted to answer the question that whether behavioralcommunication couple therapy is effective in the marital adjustment dimensions among infertile couples.

\section{Method}

This study is quasi-experimental that used pretest-posttest design with control group. According to researcher's call, among 65 couples referring to the gynecology centers in Ardabil city (Iran, in 2014), 40 couples, whose scores were a standard deviation lower than the mean value of Spinner adjustment questionnaire, were selected based on convenience sampling method. The participants randomly were assigned into two groups. In the case of subject selection, it should be noted that at least 15 participants must be allocated to each group. For the sample to be representative of population and the research to have a high external validity, 40 participants $(n=20$ per group) were considered [23].

Spinner Dyadic Adjustment Scale (DAS): Dyadic Adjustment Scale [24] has 32 questions, and measures an overall score of marital adjustment. The overall score is in range of 0 to 150 . Responding to the questions is based on a Likert scale. Individuals, whose score is 101 or less, are considered incompatible in the view point of Spinner, while those with scores higher than 101 are considered compatible. Spinner extracted 4 subscales related to the adjustment scale, which include Dyadic Consensus, Dyadic Satisfaction, Affectional Expression, and Dyadic Cohesion. Spinner stipulated the reliability of the total scale as 0.96 , Dyadic Satisfaction as 0.94, Dyadic Consensus as 0.90, Dyadic Cohesion as 0.86, and Affectional Expression as0.73.Its validity was reported as 0.86 based on Pearson Correlation with Locke-Wallace Marital Adjustment Scale [24]. In Iran, Hassan Shah determined the reliability of the scale as 0.96 and 0.92 by using split-half method and Cronbach's alpha, respectively, and reported the validity of the questionnaire as 0.85 based on its correlation with Locke-Wallace Marital Adjustment Scale [25].

After coordination with the gynecology centers and university of medical sciences, by broadcasting across Ardabil, especially at the gynecology centers, couples were invited. To meet moral considerations, research objectives were explained to the couples, and their consent was obtained by signing the consent form. After completing the DAS, 40 subjects whose scores were one standard deviation below the mean were identified. They were selected based on convenience sampling method, and randomly assigned into two groups. After explaining the objectives of the research, the study units were requested to participate in health training during this period. Before the training, both groups underwent the pre-test, and were asked to fill out the questionnaires completely based on their personality traits, and not to leave questions unanswered as much as possible. Then, the experimental group was trained on behavioral-communication couple therapy while the control group received no intervention. that Summary of the content of 
the behavioral-communication couple therapy sessions was exploration in Table1.

Group therapy consisted of 10 sessions of one hour and a half, once a week, in the place that the University determined in Ardabil city. During these meetings, and after the training, both groups were assessed. The collected data were analyzed using SPSS 19. To assess the assumption of normality of variances, to comply with the premise of peer groups based on demographic variables, and to ensure no difference between the studied groups, Kolmogorov-Smirnov statistical method, descriptive tests (frequency and percentage), Chi-square test, and multivariate analysis of covariance (MANCOVA) were used, respectively. In addition, assurances of confidentiality of information and preparation of subjects in psychological perspective to participate in the study were among the observed ethical issues.
Check the assumptions of analysis of covariance

Kolmogorov-Smirnov test was used to test the normal distribution of scores. The results of this test showed that the distribution of scores of marital adjustment and its dimensions are normal at pretest-posttest and follow-up stages and data have a normal distribution $(\mathrm{p}<0.05)$. Also, Levene's test was used to check the homogeneity of variances. Due to the lack of significance of Levene's test for pretest-posttest scores, it can be concluded that the homogeneity of variances assumption is established. Also, for the lack of interaction between groups and pre-test scores, the assumption of slope of the regression was tested. The result of this study showed that $F$ value is not significant at the level of $0.05(p<0.05)$. Thus, the slopes of the regression of marital adjustment and its dimensions are equal and there is no interaction between groups and pretest.

Table 1 Summary of the content of the behavioral-communication couple therapy sessions based on the meeting's order

\begin{tabular}{|c|c|}
\hline Session & Treatment Content \\
\hline $\begin{array}{l}\text { First } \\
\text { session }\end{array}$ & $\begin{array}{l}\text { Explaining the objectives of training and provisions of the group, overviewing Bornstein behavioral-communication } \\
\text { therapy and the concept of marital disagreement, discussing sexual desire and the history of attitudes towards it, } \\
\text { providing a list of marital problems existed among the couples through mutual cooperation between the therapist and } \\
\text { the couples }\end{array}$ \\
\hline $\begin{array}{l}\text { Second } \\
\text { session }\end{array}$ & $\begin{array}{l}\text { Evaluating communication level, communication skills, and training on proper listening skills, reflection, attention } \\
\text { to body language, expression, refraining from labeling, diagnosis; following the above techniques in self and spouse } \\
\text { behavior, naming the results of using the above techniques in self and spouse behavior, how the composition techniques } \\
\text { happen in empathy and communication of self and the partner? }\end{array}$ \\
\hline $\begin{array}{l}\text { Third } \\
\text { session }\end{array}$ & $\begin{array}{l}\text { Reviewing and reforming the communicative foundations of couples and expressing the important principles of } \\
\text { communication. Exploring the current relationship between each of the couple and his/her spouse, family, and other } \\
\text { important people in their lives. Facilitating the expression of each of the couple about the important people in their } \\
\text { lives. Establishment of individual meetings with each of the couple to explore their views more }\end{array}$ \\
\hline $\begin{array}{l}\text { Fourth } \\
\text { Session }\end{array}$ & $\begin{array}{l}\text { Reviewing and reforming the non-verbal and verbal behaviors of couples and expressing the communicative } \\
\text { differences between men and women }\end{array}$ \\
\hline $\begin{array}{l}\text { Fifth } \\
\text { meeting }\end{array}$ & $\begin{array}{l}\text { Learning the basic principles in enhancement or punishment of mutual relationships, trying to generalize the } \\
\text { therapeutic relationship to other relationships of life, especially outside the sessions, encouraging members to engage } \\
\text { in sincere relationships }\end{array}$ \\
\hline $\begin{array}{l}\text { Sixth } \\
\text { Session }\end{array}$ & $\begin{array}{l}\text { What are interpretive errors? (Naming, labeling, detection, dehumanization, and reflex response) Naming each of the } \\
\text { interpretive errors in self and the partner. What role do these errors have in personal relationship? What should we do } \\
\text { to avoid interpretive errors? And what are the results of interpretive errors in our relationships with others? }\end{array}$ \\
\hline $\begin{array}{l}\text { Seventh } \\
\text { session }\end{array}$ & $\begin{array}{l}\text { Analyzing the role of cognitive factors and cognitive errors in couples, recognizing the problems and the instability of } \\
\text { feelings, providing a list to identify inefficient practices and thoughts by the help of couples }\end{array}$ \\
\hline $\begin{array}{l}\text { Eighth } \\
\text { Session }\end{array}$ & $\begin{array}{l}\text { Recognizing and becoming familiar with negative or irrational thoughts and ideas in life through interpersonal } \\
\text { relations, teaching of reviewtechniques for the inefficient procedures and modifying these relationships, reconstructing } \\
\text { maladaptive self-talk, educating to increase positive self-talk and training problem solving skills }\end{array}$ \\
\hline $\begin{array}{l}\text { Ninth } \\
\text { Session }\end{array}$ & $\begin{array}{l}\text { Teaching communication skills and increasing positive interactions, training on sexual self-expression and emotion, } \\
\text { training on sexual intimacy }\end{array}$ \\
\hline $\begin{array}{l}\text { Tenth } \\
\text { session }\end{array}$ & $\begin{array}{l}\text { Writing farewell and treatment closure letters by therapist and couples together, as well as summarizing what was } \\
\text { gained on the treatment process and what still needs to be changed }\end{array}$ \\
\hline
\end{tabular}




\section{Results}

The results obtained on demographic characteristics of the study units such as age, education, occupation, frequency of previous pregnancy, gestational age when starting prenatal care, gestational age when starting

the study, frequency of oral examination during pregnancy, and intended or unintended pregnancy indicated that the two groups were homogeneous in terms of all these variables, as observed in Table 2 and Table 3.

Table 2 Frequency distribution of Demographic characteristics of subjects in two groups

\begin{tabular}{|c|c|c|c|c|}
\hline \multicolumn{2}{|c|}{ Demographic characteristics } & $\begin{array}{c}\text { Experimental group } \\
\mathrm{N}(\%)\end{array}$ & $\begin{array}{c}\text { Control group } \\
\mathrm{N}(\%)\end{array}$ & $\begin{array}{c}\text { p-values } \\
\text { (Chi-square test) }\end{array}$ \\
\hline \multirow{3}{*}{ Education } & Under diploma & $7(35)$ & $6(30)$ & \multirow{2}{*}{$\begin{array}{c}\mathrm{p}=0.045 \\
\mathrm{Df}=2\end{array}$} \\
\hline & Diploma & $8(40)$ & $9(45)$ & \\
\hline & Bachelor & $5(25)$ & $5(25)$ & Chi square $=21.40$ \\
\hline \multirow{2}{*}{ Job } & housewife & $14(70)$ & $12(60)$ & $\begin{array}{c}\mathrm{p}=0.020 \\
\mathrm{Df}=1\end{array}$ \\
\hline & Employed & $6(25)$ & $8(40)$ & Chi square $=7.825$ \\
\hline \multirow{3}{*}{ Age } & $20-25$ & $5(25)$ & $7(35)$ & \multirow{2}{*}{$\begin{array}{c}\mathrm{p}=0.025 \\
\mathrm{Df}=2\end{array}$} \\
\hline & $25-30$ & $10(50)$ & $8(40)$ & \\
\hline & $30-35$ & $5(25)$ & $5(25)$ & Chi square $=8.547$ \\
\hline \multirow{3}{*}{$\begin{array}{l}\text { Economic } \\
\text { status }\end{array}$} & Low & $10(50)$ & $9(45)$ & \multirow{2}{*}{$\begin{array}{c}\mathrm{p}=0.021 \\
\mathrm{Df}=2\end{array}$} \\
\hline & Moderate & $6(30)$ & $7(35)$ & \\
\hline & High & $4(20)$ & $4(20)$ & Chi square $=11.50$ \\
\hline
\end{tabular}

The results of Table 2 show the four features of the demographic variables. The results were analyzed by $\mathrm{X}^{2}$ test. According to the results of the test that proved insignificance of the demographic variables, the assumption of homogeneity of the sample is observed and the sample represents the population. In other words, the participants in the experimental and control groups were homogeneous.

Table 3 Results of Kolmogorov-Smirnov test to check the assumption of normality of variance

\begin{tabular}{lccccccccc}
\hline \multirow{2}{*}{ Dimension } & \multicolumn{3}{c}{ Experimental group } & \multicolumn{3}{c}{ Control group } \\
\cline { 2 - 8 } & Pretest & $\mathrm{p}$ & Posttest & $\mathrm{p}$ & Pretest & $\mathrm{p}$ & $\mathrm{Posttest}$ & 0.15 & 0.20 \\
\hline Dyadic Satisfaction & 0.16 & 0.14 & 0.11 & 0.20 & 0.17 & 0.10 & 0.20 & 0.15 & 0.20 \\
Dyadic Consensus & 0.14 & 0.20 & 0.16 & 0.18 & 0.15 & 0.15 & 0.20 & 0.20 & 0.02 \\
Dyadic Cohesion & 0.16 & 0.14 & 0.24 & 0.00 & 0.15 & 0.21 & 0.01 \\
Affectional Expression & 0.15 & 0.20 & 0.23 & 0.01 & 0.21 & 0.01 & 0.21 \\
\hline
\end{tabular}

As can be seen in Table 3, the null hypothesis for the normal distribution of scores is confirmed in Dyadic satisfaction, Dyadic Consensus, Dyadic Cohesion, and affectional Expression in both (experimental and control) groups. This means that the scores of both groups are normally distributed at pretest and posttest stages.

The descriptive findings (mean and standard deviation) of marital adjustment dimensions are shown in Table 4. As can be seen, there was not a significant difference between the mean scores of the experimental and those of the control groups in the pretest. However, the infertile couples, who received behavioralcommunication training, obtained higher scores in the posttest.

As can be seen in Table 4, the scores of the experimental group increased in all of the dimensions of marital adjustment. 
However, there is not much difference between pretest and posttest scores in the control group. Before using the parametric test of multivariate analysis of covariance, to comply with its assumptions, Levene's and Box's tests were used. According to the results of these tests, the assumption of equality of variance-covariance has been observed properly and therefore, using the parametric tests is allowed.

Table 3 The mean scores and standard deviation of marital adjustment dimensions in pretest and posttest

\begin{tabular}{|c|c|c|c|c|c|c|c|c|c|c|}
\hline \multirow{3}{*}{ Dimension } & \multicolumn{4}{|c|}{ Experimental group } & \multicolumn{4}{|c|}{ Control group } & \multirow{3}{*}{$\begin{array}{c}\text { Difference } \\
\text { in pretest } \\
p\end{array}$} & \multirow{3}{*}{$\begin{array}{c}\text { Difference } \\
\text { in posttest } \\
\mathrm{p}\end{array}$} \\
\hline & \multicolumn{2}{|c|}{ Pretest } & \multicolumn{2}{|c|}{ Posttest } & \multicolumn{2}{|c|}{ Pretest } & \multicolumn{2}{|c|}{ Posttest } & & \\
\hline & $\mathrm{M}$ & SD & M & SD & M & SD & M & $\mathrm{SD}$ & & \\
\hline $\begin{array}{l}\text { Dyadic } \\
\text { satisfaction }\end{array}$ & 31.30 & 4.15 & 37.30 & 4.12 & 30.85 & 5.05 & 31.30 & 5.23 & 0.23 & $\mathrm{p} \geq 0.001$ \\
\hline $\begin{array}{l}\text { Dyadic } \\
\text { consensus }\end{array}$ & 34.32 & 6.14 & 41.20 & 6.12 & 33.89 & 7.05 & 34.30 & 6.23 & 0.21 & $\mathrm{p} \geq 0.001$ \\
\hline $\begin{array}{l}\text { Dyadic } \\
\text { cohesion }\end{array}$ & 18.30 & 4.07 & 41.20 & 6.12 & 17.55 & 4.11 & 18.43 & 4.02 & 0.19 & $\mathrm{p} \geq 0.001$ \\
\hline $\begin{array}{l}\text { Affectional } \\
\text { expression }\end{array}$ & 15.30 & 3.11 & 18.30 & 2.33 & 16.55 & 3.13 & 16.99 & 3.21 & 0.18 & $\mathrm{p} \geq 0.001$ \\
\hline
\end{tabular}

Given the significance of Wilks's Lambda $(\mathrm{p}<0.001, \mathrm{~F}(32,4)=87.381)$, the factor among the subjects (behavioral-communication couple therapy) has a significant effect on the dimensions of marital adjustment in the posttest stage. In other words, the assumption that Bornstein behavioral-communication couple therapy increases the dimensions of marital adjustment of the couples is confirmed at the significance level of $\mathrm{p}<0.001$.

Table 4 The results of multivariate analysis of covariance (MANCOVA) on the scores of dimensions of marital adjustment in two groups of experimental and control

\begin{tabular}{|c|c|c|c|c|c|c|c|c|c|}
\hline \multirow{2}{*}{$\begin{array}{l}\text { Source } \\
\text { changes }\end{array}$} & \multirow{2}{*}{ Dimension } & \multirow{2}{*}{$\begin{array}{l}\text { Sum of } \\
\text { squares }\end{array}$} & \multicolumn{3}{|c|}{ Df } & \multirow{2}{*}{$\begin{array}{l}\text { Mean } \\
\text { square }\end{array}$} & \multirow{2}{*}{$\mathrm{F}$} & \multirow{2}{*}{$\mathrm{p}$} & \multirow{2}{*}{ Eta } \\
\hline & & & Group & Error & All & & & & \\
\hline \multirow{4}{*}{ Posttest } & $\begin{array}{l}\text { Dyadic } \\
\text { satisfaction }\end{array}$ & 81.51 & 1 & 32 & 40 & 81.51 & 63.50 & $\leq 0.001$ & 0.66 \\
\hline & $\begin{array}{l}\text { Dyadic } \\
\text { consensus }\end{array}$ & 154.86 & 1 & 32 & 40 & 154.86 & 127.27 & $\leq 0.001$ & 0.79 \\
\hline & $\begin{array}{l}\text { Dyadic } \\
\text { cohesion }\end{array}$ & 198.47 & 1 & 32 & 40 & 198.47 & 135.26 & $\leq 0.001$ & 0.80 \\
\hline & $\begin{array}{l}\text { Affectional } \\
\text { expression }\end{array}$ & 163.18 & 1 & 32 & 40 & 163.18 & 92.86 & $\leq 0.001$ & 0.74 \\
\hline
\end{tabular}

According to the significance of $\mathrm{F}$ in all of the marital adjustment dimensions, it can be said that the group's effect is significant. This means that after calculating the effect of pretest, the difference between the groups is significant in the adjustment dimensions. In addition, the displayed values in Table 4 indicate that in the pre-test stage, the dimensions of adjustment do not show a significant difference in the experimental and control groups. In other words, behavioral-communication couple therapy significantly increased Dyadic satisfaction, Dyadic consensus, Dyadic cohesion, and affectional expression among infertile couples in the experimental group in the posttest stage.
According to the findings, it can be said that this type of couple therapy has the capability to be trained to clients in various stages of life. Maintenance and perpetuation skills help couples maintain and operate what they have learned during the meetings and by the use of transfer and generalization skills, they can extend the trainings to other areas of life.

\section{Discussion}

The results of this study showed that behavioral-communication couple therapy had a significant effect on the increase of adjustment in infertile couples. The results were similar to those of Sodaniet al. [15], 
Markman et al. [17], Johnson et al. [18], and Hoyer et al. [19], indicating that treatment methods used to settle couples' problems can have a significant impact on increasing compatibility. In the meantime, the impact of behavioral couple therapy is impressive in infertile couples. From the perspective of enriching communication, an efficient behavioral-communication couple therapy can keep couples relationships healthy, create the ability to maintain protection, problem solving and interacting without bias, ability to express and satisfy the desire, ability to change desires, and reduce negative interaction cycles [26]. Furthermore, cognitive-communication skills training can result in the decreased negative emotions, reduced marital conflict, and improved communication patterns and emotional intimacy among the couples [27]. In the present study, using behavioralcommunication couple therapy in infertile couples led the couples to have a higher level of communication skills and compatibility with lower levels of marital incompatibility. The study showed that the therapy increased the agreement among the infertile couples. The result is consistent with the findings of Hoyer et al. [19], Nazari [20], Murryet al. [21], and Shollenberger [22]. As a part of behavioral-communication program is to discuss problematic issues to solve them, it can be said that training couples to apply these skills in the shared life helped them reach a consensus and consultation. Thus, a positive change was occurred in the actions of the couples, and consensus and cohesion increased among them [20]. Since this approach focuses on encouraging couples to be expressive and have dialogue on various issues and increases self-esteem [21], it can improve satisfaction and expressiveness in the context of marital relationship. Due to this, the aim of this approach is to improve the quality of couples' relationships and provide a platform to satisfy needs such as love, cohesion, expressiveness, and pleasure [15]. Particularly, the promotion of empathy, communication skills, and recognizing negative thoughts and self-talk in each couple, which satisfy emotional needs and calls for transparent and sincere action among the couples, can provide infertile couples with marital satisfaction [28]. Therefore, this approach, by focusing on sexual expressiveness and facilitating feeling expression, could be effective in intimacy, solidarity, and expressing the sexual and psychological needs in infertile couples, and facilitates discussion skills in the couples on various issues [29]. The approach is more useful for the couples, who demand to restore their relationships based on close ties or for the couples, who have marital distress or have a lack of intimacy in the relationship or for those couples, one of whom suffers from certain stressful stimuli [30].

Thus, this approach teaches couples to have the ability to identify and share emotions. In addition, this approach, by creating security of intimacy among couples, mediates the relationship between these emotional skills and marital adjustment [28]. Therefore, the lack of intimate relationships between husband and wife is related to the lack of emotional expression and lack of awareness of the feelings. Thus, women in a close intimate relationship with their spouse Sal ways feel fear, embarrassment, and shame and therefore, they feel unhappy about their marriage. Much research has focused on the effectiveness of emotion-focused marital therapy to solve adjustment problems among couples. Such investigation was conducted by Johnson and Talitman [31], who showed that emotion-focused marital therapy significantly strengthens the relationship between the couples who have distress in their relationships. Thus, the use of behavioralcommunication therapy for women coping with feelings in the marriage can create effective intimate bonds with their spouses [29], and can ease the demand for support and bring comfort for avoidant couples [31]. In addition, it can increase degree of emotional, sexual, and marital intimacy, mutual trust, and marital adjustment [32].

One of the limitations of the study was the 
selection of the sample only from Ardabil city, which limits the generalization of the results to other cities. Also, lack of proper control of other influential variables on their marital adjustment, such as the Perceived social support or cultural attitudes about infertility, was another limitation of current study. Considering the sample selection dedicated to Ardabil, further researches in this regard is recommended on different cities. The results of future researches must be assessed carefully, in order to be able to generalize the findings to other cities.

\section{Conclusion}

According to the findings of this study, it can be concluded that training behavioralcommunication marital therapy skills, through the establishment of agreement between the couples and improvement of feeling expression skills, can increase the adjustment of infertile couples and enhance their satisfaction in the marital relationship. In fact, this approach increases couples' intimacy and emotional involvement, and thus reduces the conflicts among the couples. Finally, based on the conducted studies on this subject, behavioralcommunication couple therapy is suggested to help couples, especially infertile couples, solve the problems in their relationships and intimacy.

\section{Acknowledgments}

The authors appreciate the support of Ardabil University of Medical Sciences and cooperation of all the couples who participated in this study.

\section{Contribution}

Study design: ShD, HGh, NA, ZS

Data collection and analysis: ShD, HGh, NA, ZS Manuscript preparation: ShD, HGh, NA, ZS

\section{Conflict of Interest}

"The authors declare that they have no competing interests."

\section{Funding}

The author (s) received no financial support for the research, authorship and/or publication of this article.

\section{References}

1- Mazaheri MA, Kayghobadi F, Imani ZF, Ghashang N, Pato M. Problem solving strategies and marital adjustment in infertile and fertile couples. Medical Journal of Reproduction \& Infertility2001; 2(4): 22-32. 2- Noorbala AA, Ramezanzadeh F, Abedinia N, Yazdi SA, Jafarabadi M. Study of psychiatric disorders among fertile and infertile women and some predisposing factors. J Family Reprod Health2007; 1(1): 6-11.

3- Mollaiy Nezhad M, Jaaferpour M, Jahanfar S, Jamshidi R. Infertility related stress and marital life in Iranian infertile women who referred to Isfahan infertility treatment clinic. J Reprod Infertil2001; 2(1): 26-39.

4- Dargahi SH, Zeraati M, Ghamari Givi H, Ayadi N, Haghanni M. The effectiveness of emotion regulation training on emotional well-being and marital satisfaction of infertile women. Iran Journal of Nursing2015; 28(9394): 151-62.

5- Drosdzol A, Skrzypulec V. Evaluation of marital and sexual interactions of Polish infertile couples. $J$ Sex Med2009; 6(12): 3335-46.

6- Robinson SM, Alloy LB. Negative inferential style and stress- reactive rumination: interactive risk factors in the etiology of depression. Cognit Ther Res2003; 27(3): 275- 91.

7- Pasch LA, Christensen A. Couples facing fertility problems. In: Schmaling KB, Sher TG, eds. The psychology of couples and illness. Washingt DC: Ameri PsyAss; 2000. pp:241-67.

8- Monga M, Alexandrescu B, Katz SE, Stein M, Ganiats T. Impact of infertility on quality of life, marital adjustment, and sexual function. Urology2004; 63(1): 126-30

9- Peterson BD, Newton CR, Rosen KH. Examining congruence between partners' perceived infertilityrelated stress and its relationship to marital adjustment and depression in infertile couples. Family process 2003 ; 42(1): 59-70.

10- Isanezhad O, Ahmadi SA, Etemadi O. Effectiveness of relationship enhancement on marital quality of couples. International Journal of Behavioral Sciences2010; 4(1): 9-16.

11- Yaghmaei F, Mohammadi Sh, Alavi Majd H. Developing "quality of life in infertile couples questionnaire" and measuring its psychometric properties. J Reprod Infertil2009; 10(2): 137-43.

12- Da Silva SMG. Perceções de qualidaderelacional e de stressenavivência da infertilidade. 2011.

13- Ferreira M, Antunes L, Duarte J, Chaves C. Influence of infertility and fertility adjustment on 
marital satisfaction. Procedia-Social and Behavioral Sciences 2015; 171: 96-103.

14- Wood ND, Crane DR, Schaalje GB, Law DD. What works for whom: a meta-analytic review of marital and couples therapy in reference to marital distress. Am of Fam Ther2005; (33): 273-95.

15- Sodani M, Nazarifard M, Mehrabizade M. Effectiveness of behavioral-communication bernstein marital therapy on marital conflict. Journal of Clinical Psychology2010; 2(4): 1-8.

16- Berneshtain F, Berneshtain M. Marital therapy from the viewpoints of communicative behavior, Porabedinaini H, Manshaii GH. Tehran: Publications Roshd; 2006.

17- Markman HJ, Renick MJ, Floyd FH, Stanley SM, Clements M. Prevention marital distress through communication and conflict management training: A 4-5 years follow up. J Consult Clin Psychol1993; 61(1): 70-7. 18- Jahnson MD, Cohan LC, Davial J, et al. Problemsolving skills and affective expression as predictors of change in marital satisfaction. $J$ Consult \&Clin Psychol2005; 73(1): 15-27.

19- Hoyer J, Uhmann S, Rambow J, Jacobi F. Reduction of sexual dysfunction: by product of cognitive behavioral therapy for psychological disorders. Sex Relation Ther2009; 24(1): 67-73.

20- Nazari AM. Compared the effect of enrichment and communication consulting solutions based on marital satisfaction in couples both employed. [dissertation]. Tehran: Trbiyat-Moallem university 2004.

21- Murry SM, Rose P, Bellavia GM, Holmes JG. When rejection stings: How self-esteem constraints relationshipenhancement processes. $J$ PersSoc Psychol2002; 83(3): 556-73.

22- Shollenberger MA. Increasing marital adjustment in graduate students and their spouses through relationship enhancement Virginia. [dissertation]. Virginia: Polytechnic Institute and State university 2001.

23- Delavar A. Theoretical principles and practical research in the humanities and social sciences. Tehran: Publication Roshd; 2011.

24- Spanier GB, Lewis RA, Cole CL. Marital adjustment over the family life cycle: The issue of curvilinearity. $J$ Marriage Fam 1975; 37: 263-76.

25- Soltani M, Shairi M, Roshan R. The effects of emotion-focused therapy on increase marriage suitability of barren couples. Journal of Behavioral Sciences2011; 6(4): 383- 9.

26- Accordino MP, Guerney BG. Relationship enhancement couples and family outcome research of the last 20 years. The Family Journal2003; 11(2): 162-6.

27- Fincham FD, Bradbury TN. Cognitive processes and conflict in close relationships: An attribution-efficacy model. J Pers Soc Psychol1987; 53(6): 245-74

28- Martin JL, Ashby JS. Perfectionism and fear of intimacy: Implications for relationships. The Family Journal2004; 12(4): 368-74.

29- Butler MH, Dahlin SK, Fife ST. "Languaging" factors affecting clients' acceptance of forgiveness intervention in marital therapy. J Marital Fam Ther2002; 28(3): 285-98. 30- Wilson LE. Sexual satisfaction in older marriage: Effects of family of origin distress and marital distress. [dissertation]. Provo: Brigham Young University, College of psychology 2007; pp:32-40.

31- johnson SM, Talitman E. Predictors of success in emotionally focused marital therapy. $J$ Narital FamTher1997: 23(2): 135-52.

32- Dandeneau M, Johnson SM. Facilitating intimacy: A comparative outcome study of emotionally focused and cognitive interventions. J Marital Fam Ther1990; 20(4): 17-33.

Copyright $(\mathcal{C} 2016$ ASP Ins. This open-access article is published under the terms of the Creative Commons Attribution-NonCommercial 4.0 International License which permits Share (copy and redistribute the material in any medium or format) and Adapt (remix, transform, and build upon the material) under the Attribution-NonCommercial terms. 